\title{
Thomas Mann y las enfermedades infecciosas en la primera mitad del siglo XX. Parte I: Fiebre tifoidea, meningitis y sífilis
}

\author{
Walter Ledermann
}

${ }^{1}$ Centro de Estudios Humanistas Julio Prado.

Recibido: 25 de marzo de 2019

Correspondencia a: Walter Ledermann D. oncemayor@gmail.com

Thomas Mann and infectious diseases in the first half of the 20th century.
Part I: Typhoid fever, meningitis and syphilis

Surely, Thomas Mann is today a forgotten writer, with only a little and precious group of readers between our young colleagues. However, perhaps could be useful for the others some knowledge about his vision of the infectious diseases in the first half of the twentieth century, when he wrote the novels here reviewed. Typhoid fever, meningitis, tuberculosis, syphilis and cholera are present in Mann's thematic from Buddenbrooks till Doktor Faustus, always with a personal focus, more on spirit - the will to live - rather than on flesh and bones... or bacteria. One of his later and minor works let us throw an ironical glance over transplant, no so named, indeed, by Mann, who speaks of "exchange". In this first part we present typhoid fever, meningitis and syphilis.

Key words: Thomas Mann, typhoid fever, meningitis, syphilis.

Palabras clave: Thomas Mann, fiebre tifoidea, meningitis, sífilis.

\section{Propósito}

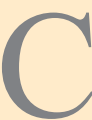

reemos no errar al considerar hoy en día a Thomas Mann como un escritor olvidado. Quizás algunos galenos en edad de retiro hayan leído en su juventud -antes de empezar a rellenar su intelecto de

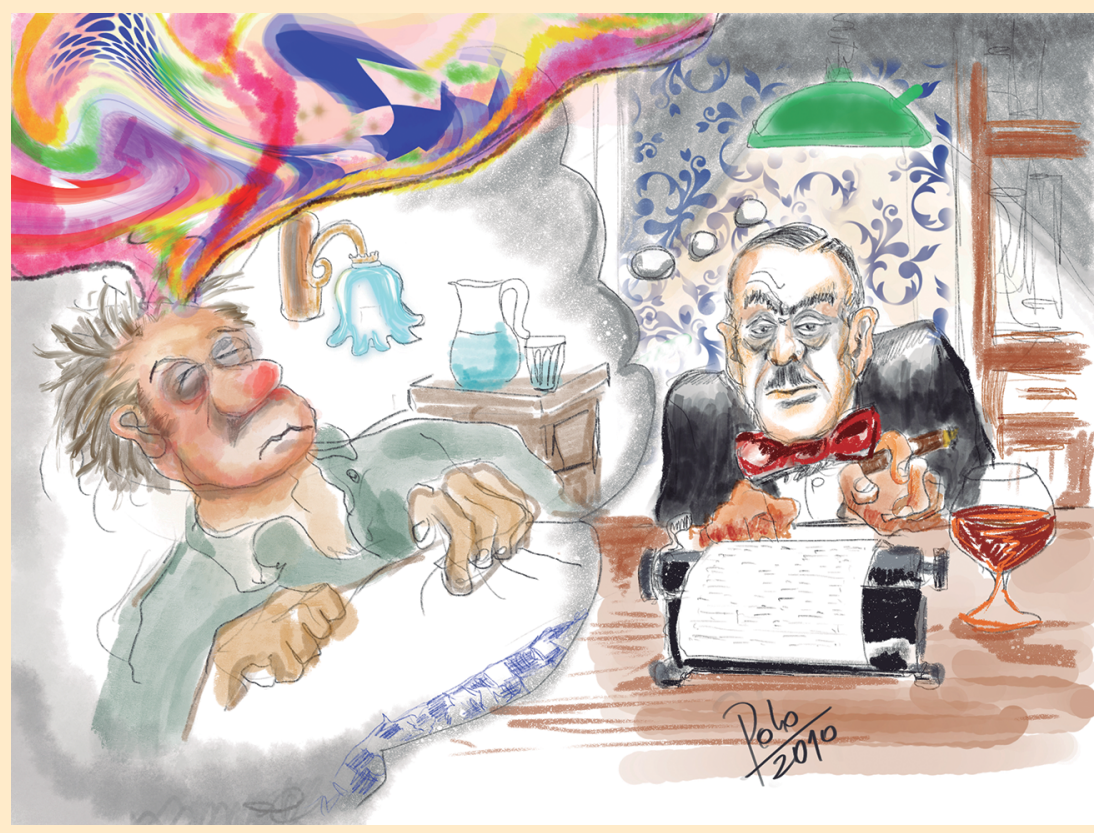

papers-La montaña mágica, su novela más relacionada con la medicina, pero con seguridad muy pocos, poquísimos, rara avis, nuestros colegas salidos de la universidad en el siglo XXI. Si los primeros podrán seguirnos en la revisión que aquí hacemos, a los últimos no les hará más daño que la lectura del Red Book.

Es muy poco lo que puede agregarse a los infinitos comentarios que señalan a Thomas Mann como escritor de excepción. Desdeñando por instinto los términos grandilocuentes y no pudiendo emplear con soltura los simples como él mismo lo recomienda, quedamos desarmados. Pero esto merece una explicación, que se encuentra en la cita siguiente: Precisamente por lo gastados que están los términos grandilocuentes, apenas sirven para nada cuando se trata de dar expresión a lo insólito, a lo extraordinario; esto se consigue en forma más satisfactoria recurriendo a las palabras modestas y sacándolas de su humildad, para elevarlas a la plenitud de su significado. Podemos, sin embargo, intentar destacar su real y sin igual mérito con las palabras de su hermano Heinrich “quien ha sido capaz de escribir Doctor Faustus", porque nunca, nunca, se podrá escribir mejor: ni siquiera él logró hacerlo, después.

Mas, no es el motivo de este artículo acumular loas sobre Thomas Mann, sino señalar un aspecto poco analizado de su producción: la presencia frecuente de la patología humana, descrita en forma tan acuciosa como original, a la par que fiel, a lo largo de su obra entera. La tuberculosis en La montaña mágica, la meningitis en Doktor Faustus, 
la fiebre tifoidea en Buddenbrooks, el cólera en Muerte en Venecia, y los trasplantes en Las cabezas trocadas, aunque sean de cabeza... son algunos de los ejemplos de entidades nosológicas tratadas desde un punto de vista muy original, que vacilamos entre llamar psicológico o espiritual. La manera en que el autor las presenta creemos que puede contribuir a conocer cómo se entendían y se vivían las enfermedades infecciosas en la primera mitad del siglo pasado, período en que Mann escribió las obras que vamos a comentar.

\section{Fiebre tifoidea}

Hemos escogido, para iniciar la ilustración de nuestras afirmaciones, las páginas dedicadas a la tifoidea en Buddenbrooks ${ }^{1}$, su primera obra magna, publicada en 1901, veintiún años después que Eberth describiera su bacilo. Hacemos presente que Mann habla del tifus, pero su descripción corresponde a la tifoidea. Y aun hoy día hay iletrados, incluso médicos, que perpetúan esta confusión.

Escrita en la era pre-antibiótica, la descripción señala las cuatro etapas clásicas, advirtiendo que la tercera es la crítica. Para la primera, en un párrafo de antología, hace una introducción notable, que nos sumerge, a quienes hemos sufrido esta odiosa salmonelosis, en una pasada pesadilla:

El hombre siente nacer en él una depresión moral, que pronto se intensifica hasta convertirse en desesperado abatimiento, y al mismo tiempo lo domina una postración física, que se extiende no sólo a los músculos y nervios, sino a las funciones orgánicas internas. El estómago empieza a ingerir por fuerza los alimentos; prodúcese una intensa necesidad de dormir, a pesar de lo cual el sueño es intranquilo, superficial, desasosegado y en ningún modo reparador; duele el cerebro; se siente encogido, como rodeado de niebla; sufre de vértigos; un dolor indefinido ataca todos los músculos y, de vez en vez, sin el menor motivo aparente, fluye sangre de la nariz.

Ya en la primera frase Thomas Mann pone las cosas claras: lo fundamental en la enfermedad es el compromiso espiritual, la depresión moral; los signos físicos vienen después y son lo accesorio. Y así leemos, algunas líneas más allá, pero más allá y no antes, el dato clínico patognomónico, de texto, la marca corporal: en la piel del vientre y del pecho se forman manchas rojas, escasas, del tamaño de lentejas, que desaparecen bajo la presión del dedo, para reaparecer cuando ésta cesa.

Viene a continuación una segunda semana terrible, una segunda semana sin cloranfenicol, donde la expresión del rostro se idiotiza ... la temperatura del cuerpo llega a 41 grados... Ahora es el cuerpo el que está enfermo; la mente, ausente, no cuenta.

En la tercera semana, prosigue, la debilidad llega al punto máximo: Nadie puede decir ya si el espiritu del cuerpo está hundido en la noche eterna, o si, extraño al estado del cuerpo, lleva una vida latente en unos sueños lejanos, profundos y silenciosos, de los cuales no llega a los espectadores ningún signo de manifestación... El cuerpo yace absolutamente insensible... Es el punto culminante, la hora crítica...

Aquí la brillante descripción hace un alto y entramos en el tratamiento, uno de esos tratamientos antiguos que, al saltar a nuestra vista en una vieja publicación médica, nos hace sonreír, entre desdeñosos y nostálgicos: una habitación amplia, máxima limpieza, dieta rigurosa... $\mathrm{Y}$ en cuanto a medicinas, una porción de yodo y yoduro potásico, quinina y antipirina, y para después del baño -iqué regalo para nuestra amada Salmonella!- coñac o champaña. El desdén del médico moderno, que aplica sin mayor meditación el esquema del cloranfenicol o del cotrimoxazol (a menos que, más exquisito, use ceftriaxona), se une a la nostalgia de un romántico pasado (que no conoció) del médico que hacía sus visitas de levita y en tilburí, en una época pausada y gentil, la era pre-Salmonella, y decimos "pre", pese a los veinte años que llevaba el descubrimiento de su etiología, pues la gente fina que se veía descrita en Buddenbrooks no leía a gentuza como Eberth y Gaffky, ni los periódicos tenían secciones para hacer divulgación "científica", que sirve sólo para confundir a los burgueses.

Surge otra vez el enfoque original del autor, que hace plantearse al médico una terrible duda diagnóstica : ¿es el tifus la desagradable consecuencia de una infección, que hubiera podido evitarse, o constituye una forma de disolución, contra la cual ninguna hierba crece en los montes? Y llegamos al final, al punto crítico en que la lucha del hombre contra la bacteria va a decidirse. Es, otra vez, la temática reiterada de la obra toda del autor de Doctor Faustus, el contrapunto entre el ser y el no ser. Aquí los comentarios sobran y hacen una ridícula compañía a la prosa soberbia del genio: que hable, entonces, Thomas Mann. Con el tifus, escribe, ocurre lo siguiente :

En los lejanos sueños febriles, durante el ardoroso extravio del enfermo, una voz inconfundible lo llama, imperiosa y segura. Es recia y vivificadora, y con su apelación patética guía al alma por un camino nuevo, entre sombras y frescores de paz. El hombre percibe con oído atento esa llamada clara, alegre, un poco burlona, que le invita al retorno, llevándolo hacia aquella región que tan lejana había dejado y que tenía ya olvidada. Si entonces se eleva persistente un sentimiento de vergüenza por su cobarde negligencia del deber, si vuelve a compenetrarse amorosa y alegremente con el mecanismo grosero y brutal que abandonaba, por muy lejos que haya llegado en aquel extraño sendero, retrocederá y vivirá. Pero si tiembla de terror y repugnancia ante esta voz de la vida que le llama; si ante estos recuerdos y estos sones alegres y retadores 
sacude la cabeza y extiende la mano con gesto repulsivo, lanzándose por el camino que le brinda la libertad... entonces no hay duda posible : morirá.

\section{Meningitis}

Desde esa primera gran novela, saltemos a su última novela gigante, cuyo nombre, por obvio, no citaremos, para comentar su enfoque de la meningitis ${ }^{2}$.

Si en Buddenbrooks era Hanno, aquel niño artista y solitario, quien renunciaba a vivir y se abandonaba a nuestra amiga, la Salmonella typhi, no menos patético e irremediable es el destino de Nepomuk, este otro niño excepcional, a quien el demonio -con los miserables y limitados medios de que dispone- arrebata al infortunado Dr. Faustus. Más nos gusta, sin embargo, el primero, más humano, más proclive al sentimiento, que este otro, personaje idealizado, criatura perfecta. Pero, en fin, las bacterias atacan a unos y a otros, indiferentemente, simpáticos o antipáticos, buenos o malos.

La primera afirmación de Mann, entrando de lleno en la patología, nos sorprende un poco, al afirmar que se trataba de una enfermedad poco frecuente en la región, pero a la cual se hallaban expuestos los niños convalecientes de sarampión y de tos ferina, lo cual nos lleva a pensar en meningitis meningocóccica.

En la descripción que hace de los pródromos vale la pena detenerse un poco. Habla de malhumor, somnolencia, fotofobia, hiperacusia y, por último, cefalea, pero no precisa la duración de esta sintomatología y, por su lenguaje tan peculiar, da a ratos, o a párrafos, la impresión que durasen varios días. Esto nos trae a la memoria otra excelente $-\mathrm{y}$ conmovedora - descripción literaria de un caso similar, hecha por otro gran autor alemán del siglo, Premio Nobel también, amigo de Mann y que, entre nosotros los chilenos, goza de más popularidad que éste: nos referimos a Hermann Hesse.

En Rosshalde ${ }^{3}$, quizás si su mejor y menos conocida novela, pero novela verdaderamente tal, el escritor suabo nos presenta al delicado y sensitivo Pierre, hijo del pintor Veraguth y muy similar a Hanno Buddenbrook, aquejado de una dolorosa enfermedad, que lo mata lenta e inexorablemente. En Pierre los pródromos abarcan un período bastante largo, una semana o más, lo que nos mueve más bien a pensar en una meningitis tuberculosa, en la que solíamos observar esta evolución a marcha lenta, para llegar a igual desenlace fatal que en la meningocóccica no tratada. Aparte de este extendido período prodrómico, es notable el caso de Hesse por el hondo dramatismo que rodea al cuadro, que va acentuándose hasta lo insoportable a medida que la enfermedad progresa, culminando con la descripción inolvidable del "grito meníngeo", que sorprende a la familia en la mesa y la hace levantarse, so- bresaltados y pálidos, teniendo clavado en la conciencia, como un cuchillo en la herida, el eco del grito horripilan$t e$, desesperado... Y dice "horripilante" un escritor que siempre se caracterizó por su exquisito lenguaje, donde los términos exagerados no tenían cabida. A propósito de estos "gritos meníngeos", Mann observa, con su sutil ironía de siempre, que sólo el médico es capaz de resistir a su impresión dolorosa, precisamente porque los reconoce como un fenómeno típico y lo típico deja frío: sólo lo individual es capaz de trastornarnos.

Pero hablábamos de los pródromos, que como tales pueden corresponder a diversas enfermedades infecciosas y, por lo tanto, no permiten hacer un diagnóstico anticipado. Sin embargo, en el año 1865 del Dr. Valderrama sostenía que esos pródromos no eran tales, que no correspondían a un período de invasión sino de estado, y suponían un proceso patológico profundo y que ha durado por algún tiempo, agregando que los niños se morían de meningitis porque sus colegas de entonces no sabían distinguir los verdaderos pródromos, que llamaba signos invasores ${ }^{4}$. ¿Cuáles eran estos signos invasores? Intranquilidad, llano inmotivado, vómitos luego de la alimentación, estreñimiento. Y agregaba que él sólo había visto tres casos y, como los reconoció en esta etapa, los tres niños se salvaron...

Entretanto, Nepomuk empeora. Aparecen, en rápida sucesión, miosis, rigidez de columna, vómitos. Se plantea el diagnóstico de meningitis cerebroespinal y se hace una punción lumbar, principalmente con fines de aliviar la presión del líquido céfalo- raquídeo. En el campo, en la preguerra, antes de la era de los antibióticos... ¿ a qué hacer cultivos ? Tanto esta primera punción, como la que hace luego el especialista venido de la ciudad, son páginas de antología.

Sobre este gran especialista conviene decir dos palabras. Desde luego, no hace nada, no puede hacer nada. $\mathrm{Si}$ condesciende a hacer otra punción y critica el tratamiento indicado por el médico rural, es sólo por justificar su viaje. No quiere que se use morfina, sino codeína y sólo codeína : según Mann, pareciera que únicamente le interesase que la enfermedad se desenvolviese correctamente y según sus normas, las de él, no las del germen.

Ahí aparece una indicación del tiempo transcurrido, al mencionarse que al cuarto día estaba en cama y tenía midriasis: Estaba tendido sobre un costado y contraído, las rodillas y codos doblados. Con las mejillas encendidas, respiraba profundamente y a largos intervalos. Los ojos no estaban completamente cerrados, pero sus párpados no dejaban entrever el azul del iris, sino únicamente sombríos reflejos negros. Las pupilas, cada día más dilatadas, invadian por completo el foco óptico. De vez en cuando, y el efecto era entonces peor, ponía los ojos en blanco, apretaba sus brazos contra el cuerpo y el espasmo, quizá ya no doloroso, contraía todos sus miembros. 
Duró cuatro días y medio. Evidentemente, una meningitis purulenta.

Volviendo al Rosshalde de Hesse, el pequeño Pierre sufrió un martirio más largo, con un breve intervalo de lucidez antes del final, que llegó precedido por el ya referido horroroso grito meníngeo. Después de eso, Pierre no recobró el conocimiento: Todo su cuerpo temblaba, como si tiritase de frio. Gritaba, débil y extraviadamente, a ratos, e inevitablemente, tras cada breve pausa impuesta por el agotamiento, volvía a levantar y dejar caer la pierna rítmicamente, como impulsado por un mecanismo de relojería. Así pasó la tarde y toda la noche... de madrugada, el débil combatiente consumió sus últimas energías y se entregó al enemigo... "Se entregó al enemigo", como Hanno, en el curso de su tifoidea en Buddenbroks.

$\mathrm{Y}$, ya que mencionamos la tifoidea de Hanno, Mann aventuraba la teoría de un fondo espiritual, anímico, que influía de manera trascendental en su evolución. Aquí, en la meningitis, postula en cambio un destino irrenunciable $\mathrm{y}$, más aun, la describe como una herramienta, bastante burda, del demonio, al exclamar Leverkühn, el Dr. Faustus: ¡Si por lo menos pudiera llevárselo de prisa! Pero los miserables medios de que dispone el raptor no deben permitirle una mayor diligencia. Una suprema injuria para los microbios, cuya existencia en 1947, fecha de publicación de su novela, Mann ya conocía largamente. Hesse, que publicó la suya en 1914, también estaba en su conocimiento, pero prefirió ignorarlos.

\section{Sífilis}

También en Dr. Faustus aparece la sífilis y con mucha mayor trascendencia, pues forma parte y es crucial para el pacto diabólico entre el músico y el demonio. Dice Mann, por boca de este pobre diablo que es Samael, que la enfermedad condiciona el genio, construyendo toda la novela sobre este postulado.

Entre las afirmaciones que hace Samael sobre la sífilis cabe mencionar que, como buen demonio alemán, le atribuye un origen americano: Entonces llegaron de las Antillas los diminutos huéspedes portadores de un nuevo flagelo... Hablo más bien de los flageladores, infinitamente pequeños, de esa Venus de cera que lleva el nombre de espiroqueta pálida. Están además muy domesticados y en los países donde penetraron hace siglos no se manifiestan de un modo escandaloso, con llagas abiertas y pestilentes $y$ narices que va cayéndose en pedazos. Tenemos, por una parte, cómo, por primera vez en sus incursiones en el campo de las enfermedades infecciosas, Mann llama al agente causal por su nombre, "espiroqueta pálida", y por otra, cómo ésta, al llevar "siglos" en América, no se manifiesta con toda su fuerza en una población ya acostumbrada a sus ataques.
Sus observaciones sobre el curso de la enfermedad denotan que el autor se documentó bien sobre el tema. Primero tenemos el contagio, que ocurre a sabiendas: el músico Leverkühn, recién llegado a Leipzig, pide a su guía que lo lleve a un buen lugar, pensando en una buena cena, pero este cicerone, viéndolo joven y saludable, se equivoca y lo lleva a un prostíbulo, donde el contacto del brazo desnudo de Esmeralda, la hetaira, la muchacha de nariz achatada espanta y hace huir al casto artista; pero el daño ya está hecho y el músico vuelve en su busca y la sigue hasta Presburgo, donde la encuentra recién salida del hospital, y aunque ella le advierte de su enfermedad venérea, diciéndole que su cuerpo era peligroso, el pacto se consuma con esta relación, apareciendo al poco tiempo una molestia local. Segundo, esta molestia local, es decir, el chancro, que Mann no describe, lo lleva a consultar dos médicos, elegidos de una lista de colegiados y que el demonio se encargará de eliminar oportunamente: la primera elección es mala, el médico es descrito como chapucero y fallece inexplicablemente a mitad del tratamiento, obligando al paciente a una segunda elección, más desafortunada aun que la primera, siendo el galeno detenido por la policía, con lo cual Leverkühn decide abandonar toda terapia, que de nada hubiera servido por lo demás, con tanto mayor motivo cuanto que la molestia local no tardó en desaparecer y puedo asegurar, dispuesto a mantener lo que digo contra cualesquiera dudas de carácter facultativo, que nunca se manifestaron síntomas secundarios de ninguna clase.

Así parece saltarse Mann la sífilis secundaria, pero luego agrega que tiempo después - no precisado - sufrió un vahido que lo hizo vacilar y lo obligó a acostarse... siguieron dos dias de jaqueca quizá más fuerte que de ordinario, pero no eran en sí ninguna novedad. No se habla de exantema ni de otras lesiones mucocutáneas, cuya falta Mann atribuye a que el tratamiento específico había limitado sensiblemente los efectos de la infiltración cutánea general, salvando con elegancia esta desagradable segunda etapa, para pasar luego a las fases de latencia y terciaria. Pero dejemos que Samael las describa, como se las describió al enfermo, mencionando el tropismo bacteriano:

- La metaespirocatosis es el proceso meníngeo y puedo asegurarte que todo ocurre como si algunos de los diminutos tuvieran una preferencia especial por la región superior, una pasión por las meninges, la duramadre, la aracnoides y la piamáter, protectoras de la blanda masa encefálica, y hacia alli se acumulan ávidamente desde el momento en que se inicia la infección general... algunos doctores pretenden y juran que entre los diminutos hay verdaderos especialistas del cerebro... Pero ocurre exactamente lo contrario. Es el cerebro el que aspira a la visita... atrae e invita, como si se impacientara de esperar. ¿Recuerdas lo que dijo el filósofo? "Las 
acciones de los agentes se producen en los pacientes predispuestos".

A continuación Samael afirma que cuatro años después del contagio, hoy, el foco existe en tu cerebro, pequeño, reducido, finamente circunscrito - pero existe. El hogar, el taller de los diminutos, que alli llegaron por vía líquida; el lugar de la incipiente iluminación. Y aquí hemos llegado al meollo del asunto: el treponema, al causar la enfermedad, ha iluminado la mente del músico, dando nacimiento al genio. $Y$ el demonio estipula las condiciones del pacto : le ha vendido tiempo a Leverkühn, pero no tiempo para buena vida, con vino, mujeres y canto, sino para una vida terrible, artística, creadora, genial, veintiocho años de tremenda iluminación, siendo necesario, para llevarla a cabalidad, renunciar al amor. Dice Samael :

- Asi nos las arreglamos, astutamente, para que cayeras en nuestros brazos. Hablo de mis diminutos, de Esmeralda, del contagio, de la iluminación, de todo cuanto pedían con fervor tu cuerpo, tu alma y tu inteligencia. De nosotros has aceptado tiempo, tiempo genial, tiempo fecundo, veinticuatro años completos (habían ya pasado cuatro desde el contagio).... con tal que tú renuncies (condición indispensable) a todo lo celestial y a todo lo terrenal...Tú eres nuestro prometido y, por serlo, te estará vedado el amor... En virtud de esta cláusula vimos ya como más adelante le arrebata, con ayuda del meningococo, a su amado sobrino Nepomuk.

En las páginas finales, próximo a expirar el plazo fatal, minutos antes de caer en la demencia, Leverkühn reúne a sus amigos y les narra su historia, confirmando que hizo pacto con el diablo: No creáis, queridos hermanos y hermanas, que para consumar el pacto hube de encontrarme en la encrucijada de un bosque... fue una mariposa nada más, el sólo contacto de la Hetaira Esmeralda, la bruja de lechosos filtros, a la que seguí, persiguiéndola, hasta las verdes frondosidades que son gratas a su desnudez... y alli gusté de ella, desoyendo su advertencia... Lo que hizo conmigo fue acto y veneno de amor. Así se consumó la iniciación y quedó cerrado el pacto.

Luego de pasar tres meses en un sanatorio, del cual sale más tranquilo, pese a lo cual tiene luego un intento de suicidio, Leverkühn es llevado por su madre a la casa donde vivió de niño y donde morirá sumido en la demencia, diez años después de su confesión.

\section{Resumen}

Con seguridad Thomas Mann es hoy en día un escritor olvidado, para los infectólogos y para todo el mundo, con apenas un selecto grupo de poquísimos lectores entre nuestros jóvenes colegas. No les hará mal, a éstos y a aquéllos, sin embargo, adquirir algún conocimiento de las ideas sobre las enfermedades infecciosas en la primera mitad del siglo XX, período en que Mann escribió las obras aquí comentadas: por el contrario puede resultarles particularmente útil si este conocimiento les llega a través de la visión muy personal del germano, quien pone el foco más en el espíritu -la voluntad, el alma en suma- que en el componente físico de la enfermedad, en la miseria corporal, ignorando de paso, desdeñosamente, a las bacterias causantes.

\section{Referencias bibliográficas}

1.- $\quad$ Mann, T. Buddenbrooks. Aguilar S.A., Madrid 1961.

2.- Mann, T. Doctor Faustus. Editorial Sudamericana, Buenos Aires 1950.

3.- Hesse, H. Rosshalde. Aguilar S.A., Madrid 1963.

4.- Valderrama, A. Estudio sobre el período de invasión de las enfermedades. Anales Universidad de Chile 1863; XXII: 457. 